\title{
Gelation behavior as a function of concentration of sodium thiosulfate for PAM gels cross-linked with chromium
}

\author{
Sameer Al-Hajri ${ }^{1} \cdot$ Syed M. Mahmood $^{1}$ (1) $\cdot$ Saeed Akbari $^{1} \cdot$ Hesham Abdulelah $^{1}$
}

Received: 3 July 2018 / Accepted: 5 October 2018 / Published online: 12 October 2018

(c) The Author(s) 2018

\begin{abstract}
Existing reducing agents for cross-linking polymers are expensive and toxic and mostly limited for water shut off applications. A gelation study was performed on a safer, cheaper, more soluble, and short-lived gel by cross-linking polyacrylamide and chromium as a cross-linking agent using a rheometer and bead-pack porous media. The effect of concentration of sodium thiosulfate as the reducing agent was investigated to determine conditions for optimum yield strength and the gelation time and behavior which has never been published before. For a fixed minimum concentration (for the gel to form) of polyacrylamide and sodium dichromate, the gel yield strength vs. sodium thiosulfate concentration showed a somewhat bell-shaped curve initially increasing, reaching a peak at $2000 \mathrm{ppm}$, and then starting to decrease. The gelation formed by sodium thiosulfate was comparatively weak and short lived as compared to the ones formed by other reducing agents. Gel started to form instantaneously, reached a peak in $2 \mathrm{~h}$, began to decrease, and then stabilized at $40 \mathrm{cp}$. The mobility reduction trends were similar to the yield strength curve. The short-lived gel could be useful to improve the waterflood mobility ratio far away from the wellbore without compromising on ease of injectivity.
\end{abstract}

Keywords Cross-linking agent $\cdot$ Polymer gel $\cdot$ Sodium dichromate $\cdot$ Sodium thiosulfate $\cdot$ Yield strength $\cdot$ Gelation time

\section{Introduction}

The hydrocarbon reservoirs initially produce hydrocarbon due to their high pressure. Up to $95 \%$ of the hydrocarbon could remain in the reservoir after remaining pressure is not enough to lift hydrocarbons to surface which could be thousands of feet above the reservoir.

At this point, secondary techniques are employed such as water or gas injection into the reservoir. If conditions are favorable such as the viscosity of reservoir oil is similar to the viscosity of the injected fluid, and there are no high permeability streaks, $25-60 \%$ additional recovery could be obtained. If not, the flood front may form fingering, channeling and other destabilizing phenomena.

The sweep efficiency is the key factor that determines the success of waterflooding and enhanced recovery processes (Hematpur et al. 2018; Llave 1994; Pirayesh 2012). Vertical sweep efficiencies are usually quite low due to adverse

Syed M. Mahmood

mohammad.mahmood@utp.edu.my

1 Department of Petroleum Engineering, Universiti Teknologi PETRONAS, 32610 Seri Iskandar, Perak, Malaysia mobility ratios, gravity segregations, and channeling of injected fluids through high permeability layers (Abbasi et al. 2017; Agi et al. 2018; Nasr et al. 2018). A direct solution to improve vertical sweep efficiency is to plug the high permeability layers if they exist. The published literature reports many blockingldiverting agents such as stable foams (Fitch and Minter 1976), cement and suspended particles (Botset and Fulton 1957; Goolsby 1969; Smith et al. 1969; Thomeer and Abrams 1977), grouting materials (McLaughlin et al. 1975), and gelled polymers (Felber and Dauben 1977). Low concentration solutions of polymers and crosslinking agents initially have a favorable viscosity that allows the solution to be injected deeper into the reservoir far away from the wellbore. The polymer then crosslinks with the cross-linking agent to form a gel that completely or partially plugs the contacted zone.

The treatment requires a small amount of solution because the portion of the reservoir to be treated by the cross-linked polymer is usually less than that of the portion flooded by the injected water or classical (uncross-linked) polymer solution. Although using cross-linking polymers cannot provide a significant improvement in oil recovery as compared to continuous polymer flooding, it is a more 
cost-effective hence competitive technique since only a small portion of the reservoir needs to be treated (Moradi-Araghi et al. 1988).

The cross-linked gels encounter a few challenges. The nature or the extent of the crosslink can be disturbed by the exposure of the gel to which could spell the liquids from the gel (Tanaka 1981). This disturbance is called syneresis, a phenomenon associated with polymer gels as a result of aging under harsh environment. For instance, extended exposure of a metallic cross-linked gel of polyacrylamide to high temperatures syneresis in hard brines (DiGiacomo and Schramm 1983). Moreover, syneresis may also be a result of using excessive amounts of crosslinkers.

The critical parameters to be considered in the application of gels for plugging high permeability zones are gelation time and yield strength (Nguyen et al. 2012; Summers et al. 1988; Vasquez et al. 2003). The gelation time indicates the time required for a cross-linked polymer to change from a free-flowing solution to a gel or semi-gel state and becoming difficult to pump (Hardy et al. 1999). Gelation time is observed by measuring viscosity which gradually increases as the gel starts to form, and noting the time when its value peaks or stabilizes at a specific value.

In some of the reported cases, viscosity reached infinity due to the rigid state of the cross-linked polymer (Marfo et al. 2015). However, for some gels, viscosity may reach a peak value and then start gradually decreasing due to the aging that causes aggregation/precipitation of other materials. Such a decrease in viscosity was noticed in bitumen solutions that were aged for up to 30 days causing the formation of asphaltene aggregates and aggregate clusters (Mozaffari et al. 2015).

The gelation time is a function of salinity, polymer and cross-linker concentrations and temperature (Marfo et al. 2015). (Reddy et al. 2012) developed correlations for gelation time as a function of salinity for polyacrylamide polymer and polyamide crosslinker showing a linear relationship. The gelation time increases with an increase in salinity because the common ions decrease the nucleophilic capacity (Salehi et al. 2012).

The gelation time decreases with increasing polymer and crosslinking agents concentrations because the number of active sites for the cross-linked polymer network becomes higher (El-karsani et al. 2014; Kjøniksen and Nyström 1996; Vasquez and Tuck 2015).

The rheological properties of cross-linked polymers are also significantly affected by the temperature applied. Increasing temperature accelerates molecular motion thus increasing inter/intra molecular interactions which decreases gelation time (Weng et al. 2007). However, collapse and distortion might occur at long time bonding at high temperature (Che-Hsin et al. 2001; Mozaffari et al. 2017b). In addition, there can be a kinetic energy barrier between the reactants and the product, as some nanocrystals are thermodynamically metastable species (Chen et al. 2005; Luo et al. 2018; Mozaffari et al. 2017a). Thus, depending on the materials used, increasing the temperature might be necessary to overcome this kinetic barrier for the gels to form.

Yield strength is also a very important parameter from engineering applications perspective (Nunes et al. 1982). It is the stress at which materials may deform permanently and is a practical approximation of the elastic limit (Sydansk 1990).

As mentioned earlier, gelation time and the yield strength are considered the most important parameters in polymer gel applications. The gelation time controls how far the crosslinked polymer could travel in the reservoir before gel formation. Yield strength shows the degree of effectiveness of the polymer gel at the contacted zone; in other words, it is a measure of the pressure gradient that the plugged zone can withstand without the gel being deformed and destroyed.

Equation 1 is an expression of gel's yield strength (Batycky et al. 1982):

Yield strength $=\frac{D \times \Delta p}{4 \times L}$,

where $D$ and $L$ are the diameter and the length of the beadpack, respectively. $\Delta p$ is the maximum pressure drop measured in the experimental setup.

Before the formation of the polymer gel, the solution of polymer and cross-link agent flows through the porous media until the gel forms and reduces the mobility or completely shuts off the flow (Bennetzen et al. 2014).

The mobility reduction factor (MRF) is a measure of mobility reduction due to the permeability reduction applied by polymer gels as compared to pre-gel mobility. It is defined by (Batycky et al. 1982):

$\operatorname{MRF}=\frac{(\Delta p / q) \text { After treatment }}{(\Delta p / q) \text { Before treatment }}$.

The gel formation is affected by the concentration of PAM (polyacrylamide), sodium thiosulfate and sodium dichromate. However, PAM is expensive, and sodium dichromate is much more toxic and expensive than the sodium thiosulfate. Therefore, the effects of changing the sodium thiosulfate concentration on gelation time and the gel yield strength was investigated with salinity similar to a typical field application (Sharyoof oil field, Yemen). The oxidation-reduction reaction between sodium thiosulfate and the sodium dichromate produced the chromium cation $\mathrm{Cr}^{+3}$ which acted as the cross-linking agent. 


\section{Materials and methods}

\section{Polymer}

The polymer used in this study was a PAM, (polyacrylamide, $-\mathrm{CH}_{2} \mathrm{CHCONH}_{2}-$ ) formed from subunits of acrylamide. The polymer was purchased from R\&M Chemicals, Ever Gainful Enterprise Sdn Bhd.

\section{Crosslinking agent}

The crosslinking agent $\left(\mathrm{Cr}^{+3}\right)$ used in this study was obtained by the oxidation-reduction reaction between sodium dichromate $\left(\mathrm{Na}_{2} \mathrm{Cr}_{2} \mathrm{O}_{7}\right)$ from Merck KGaA and sodium thiosulfate $\left(\mathrm{Na}_{2} \mathrm{~S}_{2} \mathrm{O}_{3}\right)$ from $\mathrm{R} \& \mathrm{M}$ Chemicals.

\section{Brine}

Brine composition was a synthetic brine solution prepared as per the composition provided by DNO ASA, a Norwegian oil and gas operating company. The brine composition of a real field (Sharyoof oil field, Yemen) was matched to make the study within the range of real reservoir brine compositions. It was prepared by mixing/dissolving sodium chloride $(\mathrm{NaCl})$, potassium chloride $(\mathrm{KCl})$, calcium chloride $\left(\mathrm{CaCl}_{2}\right)$, and magnesium chloride $\left(\mathrm{MgCl}_{2}\right)$ in distilled water. The mass ratio between $\mathrm{Na}^{+}, \mathrm{K}^{+}, \mathrm{Ca}^{+2}$, and $\mathrm{Mg}^{+2}$ was 14:1:3:1, respectively.

\section{Bead-pack flooding system}

Figure 1 shows the bead-pack system used for measuring yield strength while flowing through the porous medium. It consisted of a 30-cm long cylinder of 3-inch diameter filled with spherical glass beads (500 $\mu$ m diameter).

The packing of the glass beads was done carefully to assure that the glass cylinder is well packed and no empty pockets remain in the cylinder. A good packing was

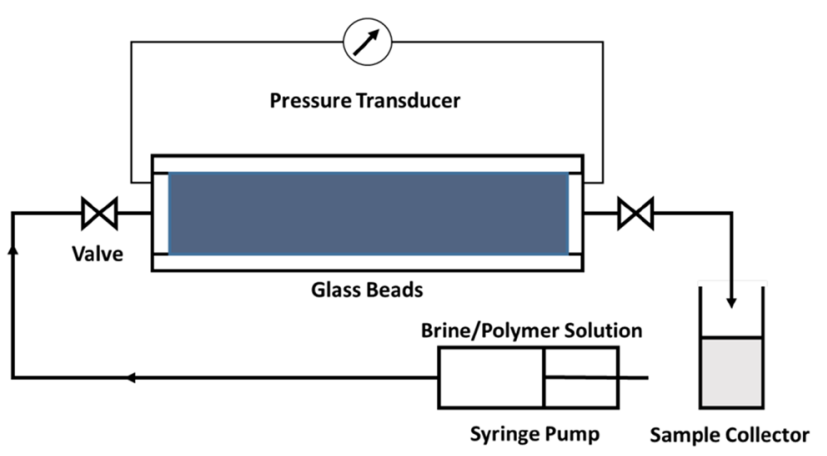

Fig. 1 The experimental set-up used in this study achieved by shaking the cylinder frequently while pressing the glass beads in as needed. After packing was completed, the air inside the cylinder was evacuated using a vacuum pump to make sure all pores (the voids) between the glass beads are filled with the injected fluid only. The presence of air would have otherwise compromised the accuracy of measurements.

The inlet of the cylinder was then connected to a syringe pump to inject brine and polymer gel solutions, while the outlet was directed to discharge the effluents into a beaker. A pressure transducer was connected between the two ends of the cylinder to record the pressure drop between the inlet $\&$ outlet automatically. The recorded pressure drop values were later converted to yield strength using Eq. 1.

\section{Viscosity measurement}

Viscosity was measured using Brookfield Model DV-III programmable rheometer (spindle 02 geometry) which is capable of measuring viscosities between 10 and $1000 \mathrm{cp}$ (mPa.s). Since viscosity plays a significant role in gelation of the cross-linked polymer, special consideration was given to its measurement.

\section{Experimental procedure}

\section{Sample preparation}

Before starting a flow test, brine solution would be prepared with the mass ratio between $\mathrm{Na}^{+}, \mathrm{K}^{+}, \mathrm{Ca}^{+2}$, and $\mathrm{Mg}^{+2}$ of $14: 1: 3: 1$, respectively.

Two thousand (2000) ppm of PAM would then be added to the brine solution in a beaker. The mixture was then thoroughly mixed using a magnetic stirrer and aged for $24 \mathrm{~h}$ to make sure all polymer is properly dissolved in the brine. One thousand (1000) ppm of sodium dichromate solution was then added to the polymer-brine solution and mixed for a couple of minutes with the magnetic stirrer.

Finally, sodium thiosulfate solution was added to the mixture and stirred for $5 \mathrm{~min}$. The concentration of sodium thiosulfate in the solution was a variable for different tests ranging from 500 to $8000 \mathrm{ppm}$.

\section{Gelation time measurement}

As soon as the sodium thiosulfate was added to the mixture in the beaker, the crosslinking agent (chromium) will be released from the sodium dichromate by a reduction reaction with sodium thiosulfate. The viscosity of the solution was measured every 20 to 30 min to determine the gelation time. 


\section{Yield strength determination}

After measurements of gelation time for each concentration of sodium thiosulfate, yield strength tests were conducted using the bead-pack flooding system described earlier. Each test started with a brine only injection to establish a baseline pressure drop and permeability before introducing any polymer or cross-linker yet.

For the first run, a solution was prepared using $500 \mathrm{ppm}$ of sodium thiosulfate, and other ingredients following the same procedure described earlier and in "Sample preparation" section. The solution was loaded into the syringe and injected into the bead-pack flooding system. After waiting for a reasonable time (a few hours), enough to complete the gelation process, brine was injected again into the system while pressure drop and permeability were determined. These values were compared with the baseline brine injection values to assess the mobility reduction due to gel formation.

This process was repeated for other sodium thiosulfate concentrations $(1000,1500,2000$ to $8000 \mathrm{ppm}$ in increment of $1000 \mathrm{ppm})$. A total of Ten runs were thus performed.

Before each run for a given sodium thiosulfate concentration, the glass beads were taken out of the bead-pack flooding system and cleaned with toluene and water, then dried and repacked.

\section{Results and discussion}

\section{Gelation time}

Figure 2 shows the cross-linking of the polyacrylamide molecules. The criterion for the gel formation is the ability to crosslink (Tobita 1998). The gelling process involves a polymer (polyacrylamide), a reducing agent (Sodium Thiosulfate), and a metal ion (Sodium Dichromate).

The gelation mechanism for polyacrylamide in the presence of metal ions is not well understood. One suggestion is that chromium serves as a crosslinker between the polyacrylamide molecules. Another idea is that chromium forms a stable dispersion in the polymer solution which results in a high viscosity liquid or gel (Prud et al. 1983).

The reaction is hypothesized in the following sequence (Clampitt and Hessert 1974; Terry et al. 1981):

- Oxidation-reduction of the metal ion $(\mathrm{Cr})$ from " +6 " valence state to " +3 " valence state:

Reducing agent $+\mathrm{Cr}^{+6} \rightarrow \mathrm{Cr}^{+3}$

- Reaction of $\mathrm{Cr}^{+3}$ with a polymer molecule:

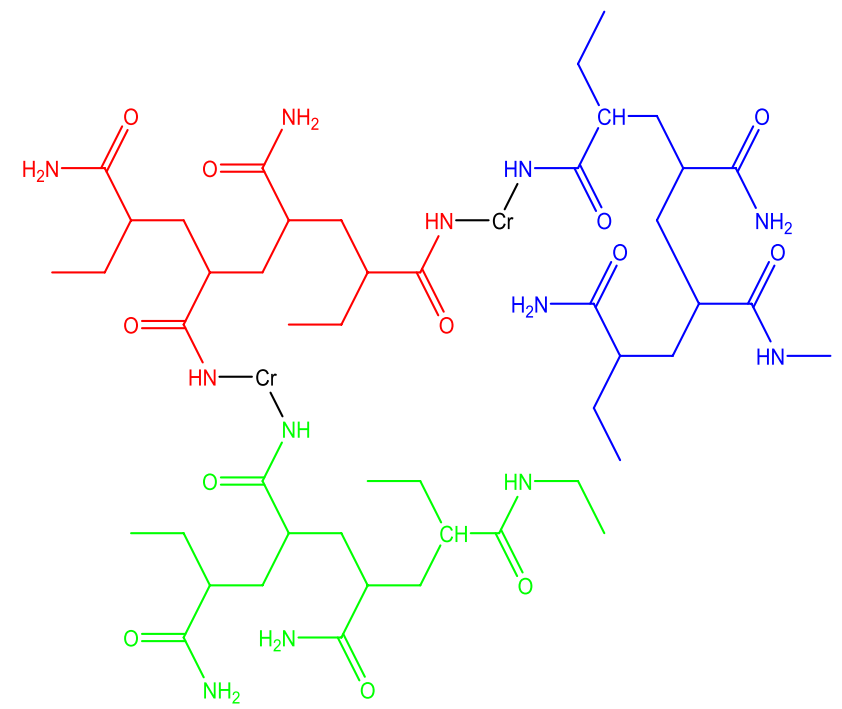

Fig. 2 Cross-linked polyacrylamide

$$
\text { Polymer }+\mathrm{Cr}^{+3} \rightarrow \text { Polymer }-\mathrm{Cr}^{+3}
$$

- The reaction of the product formed in the second step with another polymer molecule:

Polymer + polymer $-\mathrm{Cr}^{+3} \rightarrow$ polymer $-\mathrm{Cr}^{+3}-$ polymer

- The crosslinking of the polymer/metal ions continues until the gel is formed. As this reaction proceeds, the metal ions start crosslinking between polymer molecules and thus begin forming a 3D network. The gel point occurs (gel is formed) when the network becomes infinite in extent.

The gelation time is an important parameter that dictates at what distance from the injection well the gel will form. Therefore, the effect of reducing agent on gelation time was investigated in this study at ambient conditions ( $24{ }^{\circ} \mathrm{C}$ and 14.7 psia). Ten runs were performed at various concentrations of sodium thiosulfate in $2000 \mathrm{ppm}$ PAM, and $1000 \mathrm{ppm}$ sodium dichromate and viscosities were noted with time.

Figure 3 shows the viscosity vs. time results of one of the ten runs in which the highest yield strength was observed. The concentration of sodium thiosulfate for this optimum gelation was $2000 \mathrm{ppm}$. Other nine runs showed similar trends in way that higher gelation times were noted for a lower concentration of crosslinker.

The time zero in Fig. 3 corresponds to the time when the reducing agent (sodium thiosulfate) was added to the solution already containing the polymer and sodium dichromate. After a few minutes of lapse time, the chemical composition 


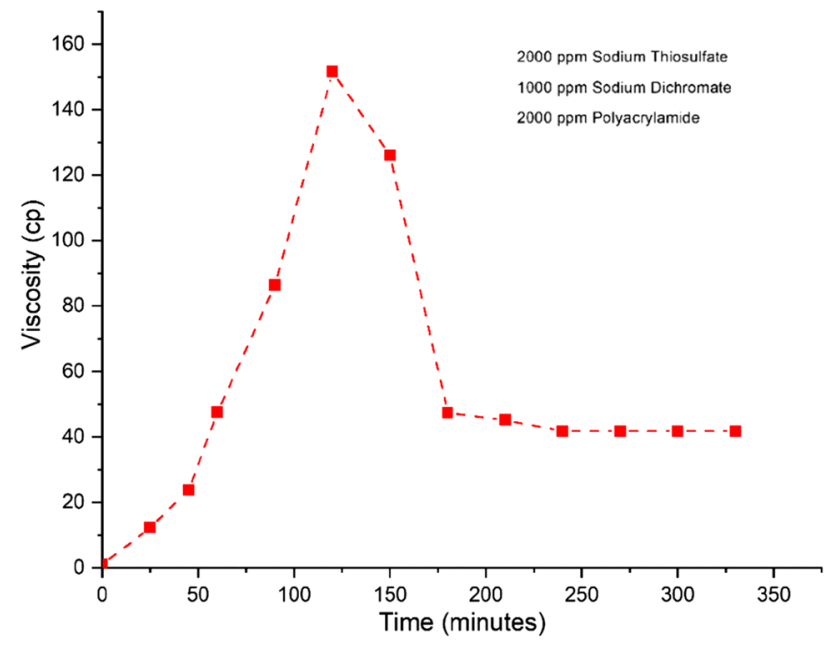

Fig. 3 Viscosity behavior of crosslink system vs. time under ambient conditions $\left(24^{\circ} \mathrm{C}\right.$ and 14.7 psia)

began to react, and viscosity began to increase significantly. However, after $25 \mathrm{~min}$, at which point viscosity had reached to approximately $12.3 \mathrm{cp}$, the gelation rate jumped suddenly, rapidly, and linearly, reaching to a peak viscosity of $151.6 \mathrm{cp}$ after $120 \mathrm{~min}$ from the start. Therefore, it is concluded that after two hours the gel was completely formed.

It is important to mention that the gelation time is usually the time required to reach an inflection in the viscosity vs. time curve, i.e., the time at which a sudden onset of sharp viscosity increase takes place. However, in this study, the gelling viscosity was initially increasing due to the crosslinking of $\mathrm{Cr}^{+3}$ ions with the polymer via the sodium dichromate group, then followed by a sharp viscosity decrease. Therefore, the gelling time for this study was defined as the time at which peak viscosity occurred.

The reason for the sharp decrease in viscosity after gelling time (reaching a peak) is not clear. It is possible that the cross-linking agent $\mathrm{Cr}^{+3}$ was responsible for the degradation of polymer gel characteristics or some other chemical resulting from the oxidation-reduction reaction. Such a behavior was reported previously by Hu 2016 (Jia et al. 2016). However, his study was for $\mathrm{Fe}^{+3}$ system and he blamed the degradation on the presence of $\mathrm{Fe}^{+3}$. Another explanation might be that this behavior is due to excessive sodium thiosulfate, which led to a more rapid sodium dichromate reduction and a higher $\mathrm{Cr}^{+3}$ ions concentration throughout the early stages of the gelation reaction, resulting in more nucleation sites and production of weaker gels.

\section{Yield strength}

To see the effect of sodium thiosulfate concentration in a solution with 2000 ppm PAM and 1000 ppm sodium dichromate, ten concentrations of sodium thiosulfate ranging from

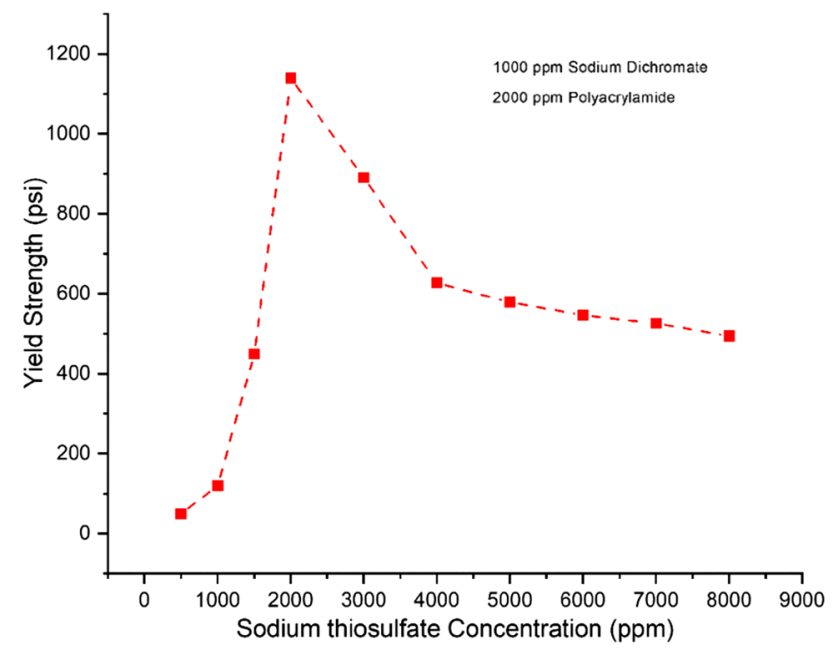

Fig. 4 Yield strength at different concentrations of Sodium thiosulfate under ambient conditions $\left(24^{\circ} \mathrm{C}\right.$ and $\left.14.7 \mathrm{psia}\right)$

500 to $8000 \mathrm{ppm}$ were tested for yield strength, which is an indication of the minimum shear stress required for displacing the gel. The sodium thiosulfate range of 500-8000 ppm was selected because the literature reports a minimum concentration of $500 \mathrm{ppm}$ to form the gel (Batycky et al. 1982).

Yield strength was calculated using Eq. 1 by measuring the pressure drop between the inlet and outlet of the "Beadpack flooding system" described in "Bead-pack flooding system".

Figure 4 shows the yield strengths of the cross-linked PAM at different concentrations of sodium thiosulfate. Interesting, the trend of yield strength was quite similar to the trend of viscosity vs. time.

The yield strength started increasing at low sodium thiosulfate concentration of $500 \mathrm{ppm}$ to $1000 \mathrm{ppm}$, beyond which yield strength jumped sharply and linearly peaked at $1140 \mathrm{psi}$ at $2000 \mathrm{ppm}$. This increase in yield strength is attributed to a higher number of crosslinking between PAM molecules caused by a higher number of released $\mathrm{Cr}^{+3}$ ions .

At the peak sodium thiosulfate, all of the $\mathrm{Cr}^{+3}$ ions have been extracted from sodium dichromate and any further increase in sodium thiosulfate concentration caused the precipitation of the PAM. This was supported by visual observations during testing process that sodium thiosulfate concentrations beyond $2000 \mathrm{pm}$ resulted in precipitation of PAM after one day. This precipitation hinders the crosslinking process thereby reducing the yield strength.

The degradation of yield strength due to precipitation starts after $2000 \mathrm{pm}$ and continues till $4000 \mathrm{pm}$ of sodium thiosulfate concentration, after which the reduction is negligibly small. The reason for the small degradation between 4000 and $8000 \mathrm{ppm}$ is not clear.

As suggested in the published literature, a minimum concentration of polyacrylamide is required for the gel to form;

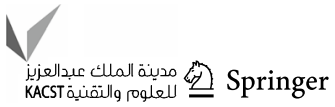


and a proper ratio between the polymer and crosslinkers is needed for optimum gelling (Grattoni et al. 2001; Koohi et al. 2010). The minimum concentration of polyacrylamide needed for gelation has been suggested to be between 1500 and 2000 (Batycky et al. 1982).

We conducted our tests with $2000 \mathrm{ppm}$ of polyacrylamide to be on the safe side. We also fixed the concentration of sodium dichromate and varied the concentration of sodium thiosulfate to find the optimum ratio between crosslinkers. An alternative approach could have been to fix the concentration of sodium thiosulfate and vary the concentration of sodium dichromate.

The optimum yield strength was observed at a concentration of sodium thiosulfate of $2000 \mathrm{ppm}$ while the concentration of sodium dichromate was held at 1000 ppm (to keep a proper ratio between polymer and crosslinker). A similar trend should be obtained if the concentration of sodium dichromate is varied and the concentration of sodium thiosulfate is fixed at $2000 \mathrm{ppm}$, i.e., optimum yield strength would have occurred at $1000 \mathrm{ppm}$ sodium dichromate concentration regardless of which one was fixed and which was varied. Using the minimal amount of sodium dichromate to form a gel is advantageous because of its toxicity and higher cost.

The yield strength data presented in Fig. 4 is not the traditional way the Oil and Gas industry uses for reservoir calculations, therefore, Fig. 5 presents a subset of this information in the form of pressure differential and permeability as noted during the brine injection after gelation vs. sodium thiosulfate concentrations. The highest differential pressure and lowest permeability were obtained at sodium thiosulfate concentration of $2000 \mathrm{ppm}$ coinciding with the yield strength.

We also measured the differential pressure and calculated the permeability (using Darcy's Law) for the brine floods

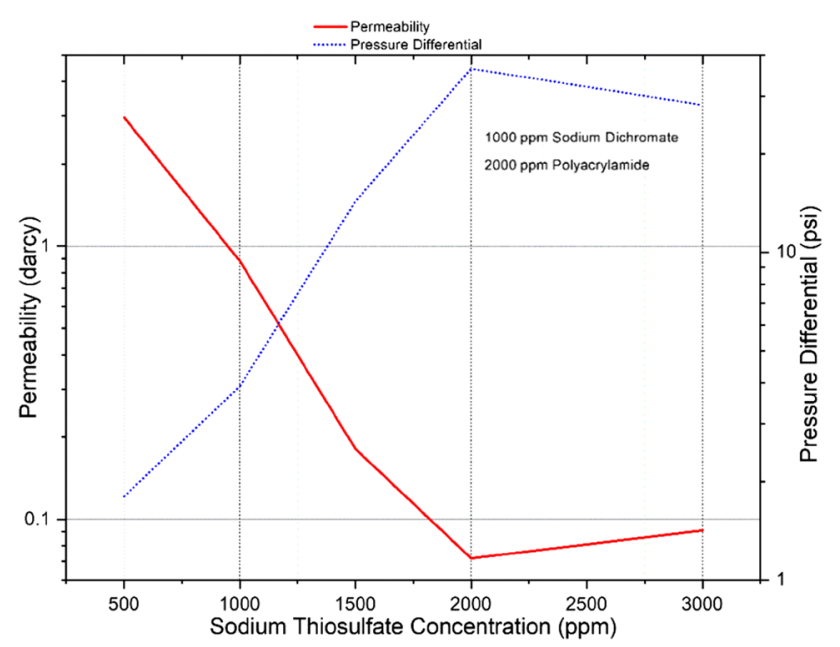

Fig. 5 Pressure drop and relative permeability behavior vs. Sodium thiosulfate concentration before the injection of polymer gel solution and used this information only to confirm gel formation.

The reduction in permeability seen in Fig. 5 could primarily be due to gel formation as evidenced by the highest permeability reduction coinciding with the strongest gel (both at $2000 \mathrm{ppm}$ of sodium thiosulfate). The second reason could be due to the precipitation of PAM as well as other components resulting from the oxidation-reduction reaction. Such precipitation, also observed in a beaker containing same polymer gel, would plug some of the pores or otherwise offer constriction reducing the permeability.

Also, the retention of PAM in the porous media by adsorption and mechanical entrapment might have contributed to this reduction as well (Agi et al. 2018; Manichand and Seright 2014; Wu et al. 2014).

\section{Mobility reduction}

The mobility is an important concept with regards to the frontal behavior of the injected fluid. As such, a plot of mobility reduction factor (MRF) as defined by Eq. 2 at ten different sodium thiosulfate concentrations is shown in Fig. 6.

The trend, of course, follows the yield strength plot but MRF gives a better feel to reservoir engineers. Just like yield strength, $2000 \mathrm{ppm}$ of sodium thiosulfate concentration was the optimum for peak mobility reduction factor of $\sim 6.5$. With further increase in the concentration of sodium thiosulfate, MRF began to drop sharply, dropping to a value of 3 at 4000 pm. From 4000 onward, the reduction in MRF continued albeit at a much slower rate, reaching to approximately two at $8000 \mathrm{ppm}$.

No further explanation is necessary since the trends are similar to the yield strength curve and the changes taking

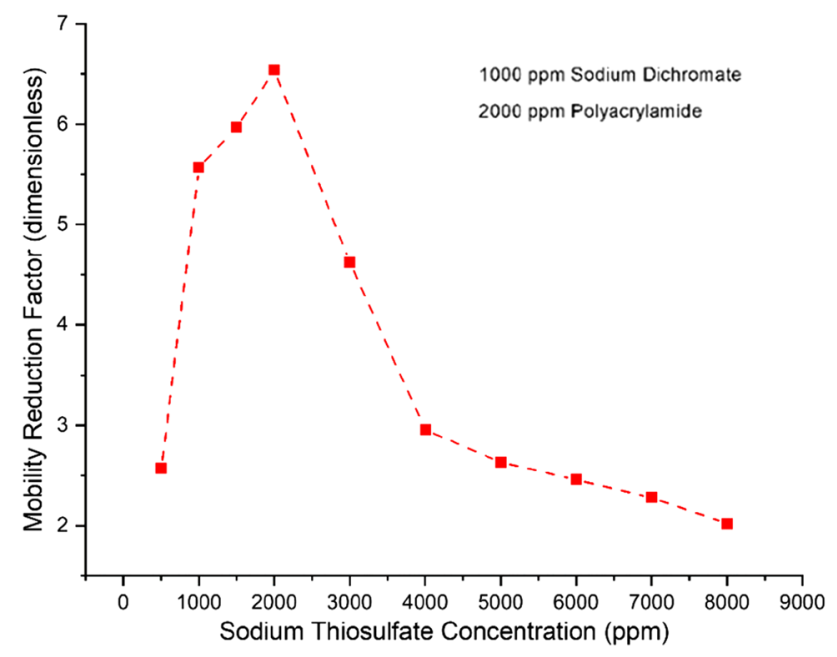

Fig. 6 Mobility reduction factor at different concentrations of Sodium thiosulfate under ambient conditions $\left(24^{\circ} \mathrm{C}\right.$ and $\left.14.7 \mathrm{psia}\right)$ 
place are governed by the same reasons as speculated with the explanation of yield strength behavior in section.

A previous study (Batycky et al. 1982) has found that mobility reduction occurs even when gels formation is not evident at low polyacrylamide concentrations and attributed this reduction to plugging of the porous media due to the precipitation of the polymer from solution. This plugging suggests that a weak or degraded gel can still be useful for EOR. In this regard, a short-lived gel offers an advantage of fewer productivity problems near the wellbore and improved mobility farther away from the wellbore.

For the research reported in this paper, all three components were premixed (as discussed in the "Sample preparation") and injected into the bead-pack flooding system and the pressure drop was monitored to ascertain mobility reduction due to gelation.

Before starting the gelation experiments as described above, tests were performed to check if gelation will occur in the absence of $\mathrm{Cr}^{+3}$. In these tests, a mixture of polyacrylamide and sodium dichromate was injected into the glass beds under similar conditions, followed by an injection of sodium thiosulfate. No increase in pressure drop (i.e., no mobility reduction) was observed indicating that gel did not form, for the obvious reason that $\mathrm{Cr}^{+3}$ was not released due to the absence of reduction reaction. This suggests that gelation behavior is not the same if $\mathrm{Cr}^{+3}$ was not introduced to the system.

\section{Conclusion}

As a result of this experimental investigation on the gelation behavior and the effect of sodium thiosulfate concentration as a reducing agent for PAM gels cross-linked with chromium, the following observations were made:

- The time for peak gelation was 120 min with a mixture of 2000 ppm sodium thiosulfate, $1000 \mathrm{ppm}$ sodium dichromate, and 2000 pm PAM. However, after reaching the peak, gel quickly start to degrade possibly due to the oxidation-reduction reaction.

- The change in yield strength with sodium thiosulfate concentration for $1000 \mathrm{pm}$ sodium dichromate and $2000 \mathrm{ppm}$ PAM showed a bell-shaped curve peaking at $2000 \mathrm{ppm}$.

- The gelation formed by sodium thiosulfate was comparatively weak and short-lived gelation as compared to other reducing agents such as potassium dichromate or thiourea systems as previously observed in the literature.

- The mobility reduction trends were similar to the yield strength curve, and the changes taking place were governed by the same reasons as for the yield strength. The peak mobility reduction factor was approximately 6.5 at $2000 \mathrm{ppm}$ of sodium thiosulfate concentration.
Acknowledgements The experimental part of this research was conducted at Universiti Teknologi Malaysia, Johor. The researchers are also grateful to EOR center and Petroleum Department of Universiti Teknologi Petronas for providing monetary support to publish this study.

Open Access This article is distributed under the terms of the Creative Commons Attribution 4.0 International License (http://creativeco mmons.org/licenses/by/4.0/), which permits unrestricted use, distribution, and reproduction in any medium, provided you give appropriate credit to the original author(s) and the source, provide a link to the Creative Commons license, and indicate if changes were made.

\section{References}

Abbasi J, Raji B, Riazi M, Kalantariasl A (2017) A simulation investigation of performance of polymer injection in hydraulically fractured heterogeneous reservoirs. J Pet Explor Prod Technol 7(3):813-820. https://doi.org/10.1007/s13202-016-0295-x

Agi A, Junin R, Gbonhinbor J, Onyekonwu M (2018) Natural polymer flow behaviour in porous media for enhanced oil recovery applications: a review. J Pet Explor Prod Technol. https://doi.org/10.1007/ s13202-018-0434-7

Batycky J, Maini B, Milosz GA (1982) Study of the application of polymeric gels in porous media. In: SPE oilfield and geothermal chemistry symposium, Society of Petroleum Engineers

Bennetzen MV, Gilani SFH, Mogensen K, Ghozali M, Bounoua N (2014) Successful polymer flooding of low-permeability, oil-wet, carbonate reservoir cores. Paper presented at the Abu Dhabi international petroleum exhibition and conference, Abu Dhabi, UAE, 2014/11/10/

Botset HG, Fulton PF (1957) Some field results on selective plugging of input wells. Producers Monthly, pp 38-41

Che-Hsin L, Gwo-Bin L, Yen-Heng L, Guan-Liang C (2001) A fast prototyping process for fabrication of microfluidic systems on soda-lime glass. J Micromech Microeng 11(6):726

Chen Y, Kim M, Lian G, Johnson MB, Peng X (2005) Side reactions in controlling the quality, yield, and stability of high quality colloidal nanocrystals. J Am Chem Soc 127(38):13331-13337. https://doi. org/10.1021/ja053151g

Clampitt R, Hessert J (1974) Method for controlling formation permeability. Google Patents

DiGiacomo P, Schramm C (1983) Mechanism of polyacrylamide gel syneresis determined by C-13 NMR. In: SPE oilfield and geothermal chemistry symposium, Society of Petroleum Engineers

El-karsani KSM, Al-Muntasheri GA, Hussein IA (2014) Polymer systems for water shutoff and profile modification: a review over the last decade. SPE J. https://doi.org/10.2118/163100-PA

Felber BJ, Dauben DL (1977) Laboratory development of lignosulfonate gels for sweep improvement. Soc Petrol Eng J 17(06):391-397

Fitch JP, Minter RB (1976) Chemical diversion of heat will improve thermal oil recovery. In: SPE annual fall technical conference and exhibition, Society of Petroleum Engineers

Goolsby J (1969) A proven squeeze-cementing technique in a dolomite reservoir. J Pet Technol 21(10):1,341-1,346

Grattoni CA, Al-Sharji HH, Yang C, Muggeridge AH, Zimmerman RW (2001) Rheology and permeability of crosslinked polyacrylamide gel. J Colloid Interface Sci 240(2):601-607. https://doi. org/10.1006/jcis.2001.7633

Hardy M, Botermans W, Hamouda A, Valdal J, Warren J (1999) The first carbonate field application of a new organically crosslinked

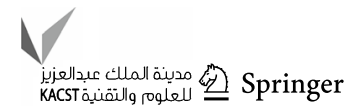


water shutoff polymer system. Paper presented at the SPE international symposium on oilfield chemistry, Houston, Texas, 1999/1/1/

Hematpur H, Mahmood SM, Nasr NH, Elraies KA (2018) Foam flow in porous media: concepts, models and challenges. J Nat Gas Sci Eng 53:163-180. https://doi.org/10.1016/j.jngse.2018.02.017

Jia H, Ren Q, Li YM, Ma XP (2016) Evaluation of polyacrylamide gels with accelerator ammonium salts for water shutoff in ultralow temperature reservoirs: gelation performance and application recommendations. Petroleum 2(1):90-97. https://doi.org/10.1016/j. petlm.2015.12.003

Kjøniksen A-L, Nyström B (1996) Effects of polymer concentration and cross-linking density on rheology of chemically cross-linked poly (vinyl alcohol) near the gelation threshold. Macromolecules 29(15):5215-5222

Koohi AD, Seftie MV, Sabet SZ (2010) Rheological characteristics of sulphonated polyacrylamide/chromium triacetate hydrogels designed for water shut-off. Iran Polym J 19(10):757-770

Llave F (1994) Field application of surfactant-alcohol blends for conformance control. In: SPE annual technical conference and exhibition, Society of Petroleum Engineers

Luo S, Zou J, Luo H, Feng J, Ng KM (2018) Synthesis of highly dispersible IZO and ITO nanocrystals for the fabrication of transparent nanocomposites in UV- and near IR-blocking. J Nanopart Res 20(4):91. https://doi.org/10.1007/s11051-018-4198-2

Manichand RN, Seright R (2014) Field vs. laboratory polymer-retention values for a polymer flood in the Tambaredjo field. SPE Reservoir Eval Eng 17(03):314-325. https://doi.org/10.2118/16902 7-PA

Marfo SA, Appah D, Joel OF, Ofori-Sarpong G (2015) Sand consolidation operations, challenges and remedy. Paper presented at the SPE Nigeria annual international conference and exhibition, Lagos, Nigeria, 2015/8/4/

McLaughlin H, Diller J, Ayres HJ (1975) Treatment of injection and producing wells with monomer solution. In: SPE California regional meeting, Society of Petroleum Engineers

Moradi-Araghi A, Beardmore D, Stahl G (1988) The application of gels in enhanced oil recovery: theory, polymers and crosslinker systems. Water-Soluble Polymers for Petroleum Recovery 299312

Mozaffari S, Tchoukov P, Atias J, Czarnecki J, Nazemifard N (2015) Effect of asphaltene aggregation on rheological properties of diluted athabasca bitumen. Energy Fuels 29(9):5595-5599. https ://doi.org/10.1021/acs.energyfuels.5b00918

Mozaffari S, Li W, Thompson C et al (2017a) Colloidal nanoparticle size control: experimental and kinetic modeling investigation of the ligand-metal binding role in controlling the nucleation and growth kinetics. Nanoscale 9(36):13772-13785. https://doi. org/10.1039/C7NR04101B

Mozaffari S, Tchoukov P, Mozaffari A, Atias J, Czarnecki J, Nazemifard N (2017b) Capillary driven flow in nanochannels-application to heavy oil rheology studies. Colloids Surf A 513:178-187. https://doi.org/10.1016/j.colsurfa.2016.10.038

Nasr NH, Mahmood SM, Hematpur H (2018) A rigorous approach to analyze bulk and coreflood foam screening tests. J Pet Explor Prod Technol. https://doi.org/10.1007/s13202-018-0545-1

Nguyen N, Tu T, Bae W, Dang C, Chung T, Nguyen H (2012) Gelation time optimization for an HPAM/chromium acetate system: the successful key of conformance control technology. Energy Sources A 34(14):1305-1317

Nunes RW, Martin JR, Johnson JF (1982) Influence of molecular weight and molecular weight distribution on mechanical properties of polymers. Polym Eng Sci 22(4):205-228. https:// doi.org/10.1002/pen.760220402

Pirayesh E (2012) Application of fracturing technology in improving volumetric sweep efficiency in enhanced oil recovery schemes (Doctoral dissertation)

Prud'homme RK, Uhl JT, Poinsatte JP (1983) Rheological monitoring of the formation of polyacrylamide/ $\mathrm{Cr}^{+3} \mathrm{Gels}$. Soc Petrol Eng J 23(05):804-808. https://doi.org/10.2118/10948-PA

Reddy BRR, Crespo F, Eoff LS (2012) Water shutoff at ultralow temperatures using organically crosslinked polymer gels. Paper presented at the SPE Improved Oil Recovery Symposium, Tulsa, Oklahoma, USA, 2012/1/1/

Salehi MB, Sefti MV, Moghadam AM, Koohi AD (2012) Study of salinity and $\mathrm{pH}$ effects on gelation time of a polymer gel using central composite design method. J Macromol Sci B 51(3):438451. https://doi.org/10.1080/00222348.2011.597331

Smith L, Fast C, Wagner O (1969) Development and field testing of large volume remedial treatments for gross water channeling. J Pet Technol 21(08):1,015 - 1,025

Summers LE, Purkaple JD, Allison JD (1988) Laboratory evaluation of crosslinked polymer gels for water diversion. In: Stahl GA, Schulz DN (eds) Water-soluble polymers for petroleum recovery. Springer, Boston, MA, p 313-328

Sydansk RD (1990) A newly developed chromium (III) gel technology. SPE Reserv Eng 5(03):346-352

Tanaka T (1981) Gels. Sci Am 244(1):124-136, 138

Terry RE, Huang C-g, Green DW, Michnick MJ, Willhite GP (1981) Correlation of gelation times for polymer solutions used as sweep improvement agents. Soc Petrol Eng J 21(02):229-235. https:// doi.org/10.2118/8419-PA

Thomeer J, Abrams A (1977) A shallow plugging-selective re-entry technique for profile correction. J Petrol Technol 29(05):571-578

Tobita H (1998) Structural requirements for gel formation. J Polym Sci B 36(11):2015-2018. https://doi.org/10.1002/(SICI)10990488(199808)36:11\%3C2015::AID-POLB23\%3E3.0.CO;2-8

Vasquez JE, Tuck D (2015) Environmentally acceptable porosity-fill sealant systems for water and gas control applications. Paper presented at the SPE Latin American and Caribbean health, safety, environment and sustainability conference, Bogotá, Colombia, 2015/7/7/

Vasquez J, Civan F, Shaw TM et al (2003) Laboratory evaluation of high-temperature conformance olymer systems. In: SPE production and operations symposium, Society of Petroleum Engineers

Weng L, Chen X, Chen W (2007) Rheological characterization of in situ crosslinkable hydrogels formulated from oxidized dextran and $N$-carboxyethyl chitosan. Biomacromol 8(4):1109-1115. https ://doi.org/10.1021/bm0610065

Wu Z, Xa Y, Cheng T, Yu J, Yang H (2014) Effect of viscosity and interfacial tension of surfactant-polymer flooding on oil recovery in high-temperature and high-salinity reservoirs. J Pet Explor Prod Technol 4(1):9-16. https://doi.org/10.1007/s13202-013-0078-6

Publisher's Note Springer Nature remains neutral with regard to jurisdictional claims in published maps and institutional affiliations. 